\title{
Combined Pulse-Width Modulation of Dual Active Bridge DC-DC Converter to Increase the Efficiency of Bidirectional Power Transfer
}

\author{
Muhammad Hazarul Azmeer bin Ab Malek* Member, Hiroaki Kakigano* Member \\ Kiyotsugu Takaba* Member
}

(Manuscript received March 28, 2017, revised Sep. 19, 2017)

\begin{abstract}
A dual active bridge (DAB) dc-dc converter is suitable for bidirectional high-power transfer. However, it has a limited soft-switching range and a high peak current during low power transfer with traditional phase-shift modulation (PSM) when there is a variation in the input/output voltage. To overcome solve this difficulty, this paper proposes a new modulation strategy, combined pulse-width modulation (CPWM) which combines single pulse-width modulation (SPWM) and dual pulse-width modulation (DPWM), with a unified fundamental phase $\varphi_{\mathrm{f}}$ for a wide power transfer range. Unlike previous modulation strategies, CPWM is applicable for bidirectional power transfer. In order to combine SPWM and DPWM, this study comprehensively analyzes the soft-switching range and the peak current of PSM, SPWM, and DPWM. The CPWM strategy is experimentally tested using a $1.6 \mathrm{~kW}$ prototype to verify the improvement in efficiency and its bidirectional power transfer capability. The experimental results show efficiencies of both positive and negative power transfers were improved by using CPWM.
\end{abstract}

Keywords: dual active bridge, bidirectional power transfer, modulation strategy, soft-switching range, pulse-width modulation

\section{Introduction}

Renewable energy systems, including photovoltaic systems and wind power generation systems, have been rapidly increasing in number. Since these systems cannot provide stable power, their unstable outputs should be compensated by integrating the renewable energy systems with energy storage systems (ESS) to use them in utility grids. Bidirectional dc-dc converters form the cores of the ESS. They are widely used not only for renewable energy systems but also for hybrid car systems and uninterrupted power supplies. There are two types of bidirectional $\mathrm{dc}-\mathrm{dc}$ converters: isolated and nonisolated. If a large voltage gain is required, the non-isolated converters require more switches and bigger capacitors ${ }^{(1)-(5)}$. The isolated dc-dc converters can easily achieve large voltage gains by adjusting the winding ratio of the transformer. The isolated dc-dc converters come in many types ${ }^{(6)-(15)}$. In this study, a single-phase dual active bridge (DAB) converter is chosen because of its soft-switching capability, bidirectional buck-boost operation, and simple circuit configuration ${ }^{(15)}$.

Most of the literature on DAB converters focus on the optimal modulation strategy to operate in a wide range of voltage variation and in a wide power range ${ }^{(15)-(23)}$. The DAB converter modulation has three degrees of freedom $\left(\varphi, \tau_{\mathrm{P}}, \tau_{\mathrm{S}}\right)$. The phase $\varphi$ is the phase shift between the square voltage of the two bridges. The primary and secondary voltage widths $\left(\tau_{\mathrm{P}}, \tau_{\mathrm{S}}\right)$ are the phase shifts between the legs within a bridge. The phase-shift modulation (PSM) is the most commonly

\footnotetext{
* College of Science and Engineering, Ritsumeikan University 1-1-1, Noji-Higashi, Kusatsu, Shiga 525-8577, Japan
}

used strategy to regulate power flow because it has only one degree of freedom $(\varphi)$. When the input or the output has a wide voltage variation, the traditional PSM has a limited softswitching range and a high circulation current at a low power range ${ }^{(15)}$. The single pulse-width modulation (SPWM), which is also known as the trapezoidal modulation ${ }^{(16)}$, has two degrees of freedom $\left(\varphi, \tau_{\mathrm{P}}\right)$. It can reduce the peak current and slightly increase the soft-switching range at a medium power range ${ }^{(17)(18)}$. The dual phase shift (DPS) modulation also has two degrees of freedom $\left(\varphi, \tau_{\mathrm{P}}=\tau_{\mathrm{S}}\right)$ but it is used to reduce high inrush current ${ }^{(19)}$. The dual pulse-width modulation (DPWM), which is also known as the triangular modulation or the triple phase shift, has three degrees of freedom $\left(\varphi, \tau_{\mathrm{P}}\right.$, $\left.\tau_{\mathrm{S}}\right)^{(20)}$. It can increase the soft-switching range and reduce the high circulating current at a low power range.

These modulations can be combined to form a modulation strategy to extend the soft-switching range. Great improvement in efficiency especially at low power transfer has been reported ${ }^{(20)-(24)}$. The modulation strategy proposed in (21) has analyzed modulations that can operate with the optimal efficiency, although 'the determination of the three degrees of freedom is unclear. The determination of the three degrees of freedom is important to ensure a smooth transition between the modulations. The modulation strategies in (20) (22) (23) have an algorithm of the three degrees of freedom to operate in the soft-switching. Especially, the modulation strategy in (23) has mathematically determined the three degrees of freedom to operate in soft-switching even when there is a wide voltage variation. However, the algorithm of these modulation strategies are only able to transfer power to one direction. The algorithm requires improvement to transfer power bidirectionally. Since the DAB transfers power bidirectionally, it 


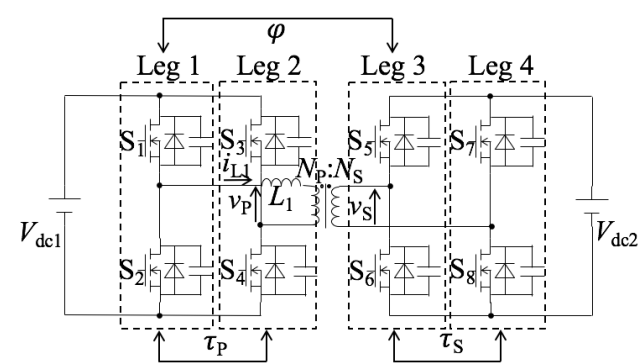

(a)

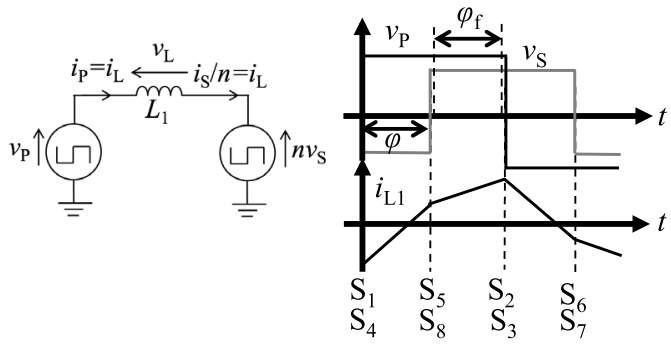

(b)

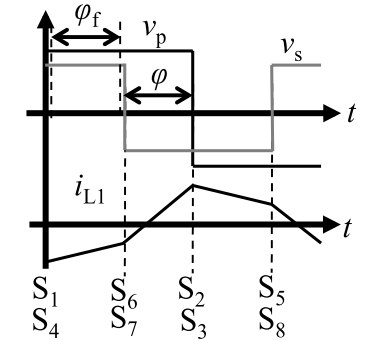

(d)

Fig. 1. Dual active bridge. (a) Circuit diagram. (b) Ideal equivalent circuit. (c) Phase-shift modulation, $r<1$, $\varphi>0$ (d) Phase-shift modulation, $r<1, \varphi<0$. where $r=n V_{\mathrm{dc} 2} / V_{d c 1}, n=N_{\mathrm{P}} / N_{\mathrm{S}}$

is important for the modulation strategy to transfer power to negative direction too.

This paper proposes an algorithm of a new modulation strategy, combined pulse-width modulation (CPWM) to transfer power smoothly and bidirectionally in a wide voltage variation by combining the SPWM and the DPWM with a unified fundamental phase $\varphi_{\mathrm{f}}$. This paper includes analyses of the PSM, the SPWM, and the DPWM including power transfer, soft-switching range, and peak current to operate with a low peak current even if there is a wide voltage variation in the input or the output voltage. This paper also discussed on how the DPWM can increase the soft-switching operation.

This paper is organized as follows: Section 2 introduces the DAB dc-dc converter. Section 3 analyses the power transfer, peak current, and soft-switching range of the three types of modulations. The CPWM is presented in Section 4. The experimental results are presented in Section 5 to demonstrate the advantages of the CPWM.

\section{DAB DC-DC Converter}

Figure 1(a) displays a DAB dc-dc converter circuit. It consists of primary and secondary full bridges (FB1 and FB2), and a transformer constructed with a relatively high leakage inductance $L_{1}$. Each power switch $\left(\mathrm{S}_{1}-\mathrm{S}_{8}\right)$ has a parasitic capacitor and an antiparallel diode. In the primary bridge, $S_{1}$ and $S_{2}$ are in leg 1 , and $S_{3}$ and $S_{4}$ are in leg 2 . In the secondary bridge, $S_{5}$ and $S_{6}$ are in leg 3 , and $S_{7}$ and $S_{8}$ are in leg 4 . FB1 converts the primary de voltage supply $V_{\mathrm{dc} 1}$ to a 2 or 3 level square ac voltage (primary square voltage $\left.v_{\mathrm{p}}\right)$ by switching four power switches $\left(\mathrm{S}_{1}-\mathrm{S}_{4}\right)$. FB2 converts the secondary dc voltage supply $V_{\mathrm{dc} 2}$ to a 2 or 3 level square ac voltage (secondary square voltage $v_{\mathrm{s}}$ ) by switching the other four switches $\left(\mathrm{S}_{5}-\mathrm{S}_{8}\right)$. The primary and secondary windings of the transformer $\left(N_{\mathrm{P}}\right.$ and $\left.N_{\mathrm{S}}\right)$ determine the primary and secondary square voltages, and the potential difference results in the leakage inductance voltage $v_{\mathrm{L} 1}$. Shifting the fundamental phase $\varphi_{\mathrm{f}}$ between the middle of primary and secondary square voltages regulates the power flow ${ }^{(20)}$. The details are discussed in section III. The current $i_{\mathrm{L} 1}$ flowing through the transformer depends on the values of the leakage inductance $L_{1}$ and the switching frequency $f_{\mathrm{S}}$. The equivalent circuit for the ideal converter is given in Fig. 1(b).

\section{Modulation Analysis}

A modulation consists of the phase $\varphi$, the primary square voltage $v_{\mathrm{P}}$, and the secondary square voltage $v_{\mathrm{S}}$. Figure 2

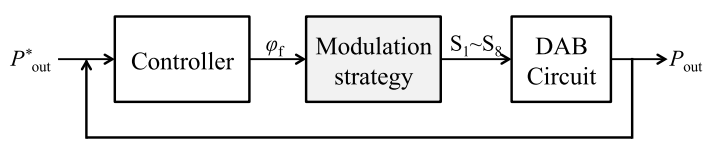

Fig. 2. Dual active bridge closed-loop control block diagram

shows that the modulation strategy determines the switching waveform for each power devices $S_{1}-S_{8}$. Although the power transfer depends on the value of the fundamental phase $\varphi_{\mathrm{f}}$, the power analysis is done based on $\varphi$ because it simplifies the subsequent explanation. Figures $1(\mathrm{c})$ and 1(d) demonstrate the difference between the phase $\varphi$ and the fundamental phase $\varphi_{\mathrm{f}}$. The relation between $\varphi_{\mathrm{f}}$ and $\varphi$ can be expressed by

$$
\varphi_{\mathrm{f}}=\varphi+\frac{\tau_{\mathrm{S}}-\tau_{\mathrm{P}}}{2} .
$$

In this section, the PSM, the SPWM, and the DPWM are compared by analyzing their power transfers, peak currents, and ZVS ranges. During the analyses, the primary voltage $V_{\mathrm{dc} 1}$ is considered to be higher than the secondary voltage $n V_{\mathrm{dc} 2}$. The voltage ratio $r=n V_{\mathrm{dc} 2} / V_{\mathrm{dc} 1}$ depends on the winding ratio $n$, the primary voltage $V_{\mathrm{dc} 1}$, and the secondary voltage $V_{\mathrm{dc} 2}$. The reason why the primary voltage $V_{\mathrm{dc} 1}$ is higher than the product of the secondary voltage and the winding ratio $n V_{\mathrm{dc} 2}$ is that we designed this algorithm under the condition that the voltage ratio is less than $1(r<1)$. The voltage ratio becomes less than 1 when the primary voltage $V_{\mathrm{dc} 1}$ is higher than the value $n V_{\mathrm{dc} 2}$. When we use the algorithm under the condition that the value $n V_{\mathrm{dc} 2}$ is higher than the primary voltage $V_{\mathrm{dc} 1}$, the higher voltage side $n V_{\mathrm{dc} 2}$ is set to be the primary voltage and the lower voltage side $V_{\mathrm{dc} 1}$ is set to be the secondary voltage. Then, the voltage ratio can be kept less than 1 . These are necessary for studying the advantages and disadvantages of each modulation.

Another important thing to know is the soft-switching conditions. Theoretically, all power devices will operate in the zero voltage switching (ZVS), if all the leakage inductance current conditions below are satisfied:

$$
\begin{aligned}
& i_{\mathrm{L} 1}(0)<0 \text { for } \operatorname{leg} 1, \\
& i_{\mathrm{L} 1}\left(\tau_{P}\right)>0 \text { for leg } 2, \\
& i_{\mathrm{L} 1}(\varphi)>0 \text { for leg } 3, \text { and } \\
& i_{\mathrm{L} 1}\left(\varphi+\tau_{\mathrm{S}}\right)<0 \text { for leg } 4 .
\end{aligned}
$$

In the ZVS operation, negative current flows through the antiparallel diode of the power device and the charges in the parallel parasitic capacitor are completely discharged. Then, the power device is turned on while the voltage across it is 


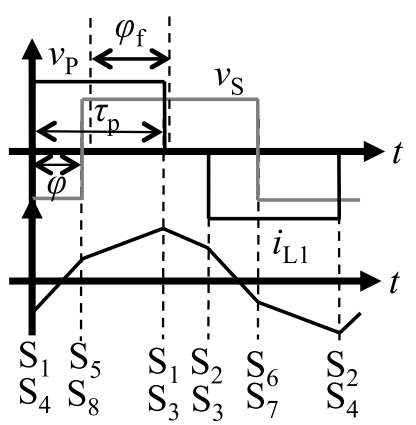

(a)

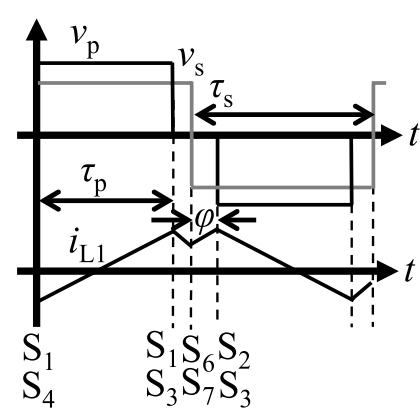

(b)

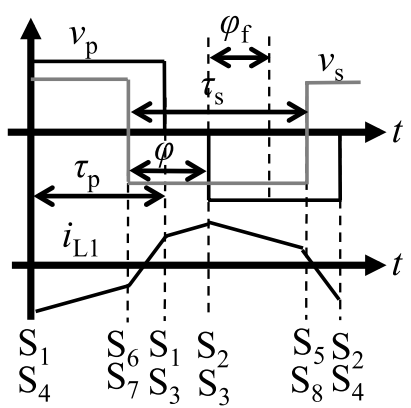

(c)

Fig. 3. Singe pulse-width modulation (a) $\tau_{\mathrm{P}}<\pi, r<1, \varphi>0$. (b) $\tau_{\mathrm{P}}<\pi, r<1, \varphi<0,|\varphi|<\left(\pi-\tau_{P}\right)$. (c) $\tau_{\mathrm{P}}<\pi, r<1, \varphi<0,|\varphi|>\left(\pi-\tau_{P}\right)$

zero.

3.1 Phase-Shift Modulation (PSM) This modulation is widely used due to its simplicity of controlling the magnitude and direction of power by shifting the phase, $\varphi$. In Figs. 1(c) and 1(d), the primary and secondary voltage widths are fixed at $\pi$. Since the primary and secondary voltage widths are equal, the fundamental phase is the same as the phase, namely $\varphi=\varphi_{\mathrm{f}}$. The power transfer is given by

$$
P_{\mathrm{o}}=\frac{r V_{\mathrm{dc1}}^{2}}{2 \pi f_{s} L_{1}} \varphi\left(1-\frac{|\varphi|}{\pi}\right)
$$

where $r=n V_{\mathrm{dc} 2} / V_{\mathrm{dc} 1}$ is the voltage ratio, $n=N_{\mathrm{P}} / N_{\mathrm{S}}$ is the winding ratio, and $f_{\mathrm{S}}$ is the switching frequency. When $\varphi>0$, power is transferred from $V_{\mathrm{dc} 1}$ to $V_{\mathrm{dc} 2}$. When $\varphi<0$, power is transferred from $V_{\mathrm{dc} 2}$ to $V_{\mathrm{dc} 1}$. At $\varphi= \pm \pi / 2$, the converter reaches the maximum power transfer

$$
P_{\max }=\frac{n V_{\mathrm{dc} 1} V_{\mathrm{dc} 2}}{8 f_{\mathrm{S}} L_{1}}
$$

This implies that the value leakage inductance $L_{1}$ and the switching frequency $f_{\mathrm{S}}$ affect the power transfer across the transformer. The peak current for the PSM is

$$
i_{\text {peak }}=\frac{n V_{\mathrm{dc} 2}(2 \varphi-\pi)+V_{\mathrm{dc} 1} \pi}{4 \pi f_{\mathrm{S}} L_{1}}, \ldots \ldots \ldots \ldots \ldots \ldots
$$

This confirms that the peak current is not zero even if the phase $\varphi$ is zero when $r \neq 1$. There is a high peak current in the converter even if there is no power transfer between the primary and secondary sides.

Theoretically, the ZVS is satisfied if the minimum value of the phase is

$$
\varphi_{\min }>\frac{\pi}{2}(1-r)
$$

The ZVS capability reduces if the voltage ratio is not equal to $1(r \neq 1)$.

3.2 Single Pulse-Width Modulation (SPWM) This modulation has two degrees of freedom, which are the phase $\varphi$ and the primary voltage width $\tau_{\mathrm{P}}$. Figures 3(a), 3(b), and 3 (c) implies that the secondary voltage width is fixed at $\pi$. The modulation is not widely used alone because the direction of the power transfer does not correspond to the value of $\varphi$. The value of the phase $\varphi$ is different from the value of the fundamental phase $\varphi_{\mathrm{f}}$ in the SPWM. The power transfer is given by

$$
P_{\mathrm{o}}=\frac{r V_{\mathrm{dc1}}^{2}}{4 \pi^{2} f_{s} L_{1}}\left(2 \varphi \tau_{\mathrm{P}}-2|\varphi| \varphi-\tau_{\mathrm{P}}^{2}+\tau_{\mathrm{P}} \pi\right)
$$

When $\tau_{\mathrm{P}}$ is equal to $\pi$, (7) is identical to (3). This means that the power transfer of the SPWM depends on the phase and the primary voltage width.

The peak current for the SPWM is

$$
i_{\text {peak }}=\frac{n V_{\mathrm{dc} 2}\left(\pi-2 \tau_{\mathrm{P}}\right)+V_{\mathrm{dc} 1} \tau_{\mathrm{P}}}{4 \pi f_{\mathrm{S}} L_{1}}
$$

The peak current is not zero even if $\varphi=\tau_{\mathrm{P}}=0$ when the voltage ratio $r \neq 1$. In fact, the circulation current is generated due to the presence of the secondary voltage width $\tau_{\mathrm{S}}$. The advantage of this modulation is that it has a lower peak current for medium to high power transfer than the PSM.

Reference (17) shows that only leg 3 and leg 4 are operating in hard-switching at low power. Since the leakage current of the secondary voltage at $i_{\mathrm{L} 1}(\varphi)$ is the same as that at $-i_{\mathrm{L} 1}(\varphi+\pi)$, one leakage current condition $i_{\mathrm{L} 1}(\varphi)>0$ is enough to achieve the ZVS operation for leg 3 and leg 4 . The $\mathrm{ZVS}$ is satisfied if the minimum value of the phase is

$$
\varphi_{\min }>\frac{\pi}{2}\left(\frac{\tau_{\mathrm{P}}}{\pi}-r\right)
$$

The converter operates in the ZVS starting from $\varphi>0$ if the primary voltage width is $\tau_{\mathrm{P}}=\pi r$. In order to match $\varphi$ of the SPWM with that of the PSM, the phase is expressed using the fundamental phase by using (1). From (1) and (9), the minimum fundamental phase for the SPWM is given by

$$
\varphi_{\mathrm{f}_{-} \min }>\frac{\pi}{2}(1-r)
$$

The soft-switching range of the SPWM is equal to that of the PSM based on the fundamental value. Since reducing the primary voltage width to $\tau_{\mathrm{P}}=\pi r$ reduces the power transfer, the ZVS range capability increases. For example, when the voltage ratio $r$ is 0.5 , the ZVS range of the SPWM increases up to $33 \%$ compared to the ZVS range of the PSM. Figure 3(b) displays an example of the modulation that does not satisfy the conditions (9) and (10).

3.3 Dual Pulse-Width Modulation (DPWM) This modulation has three controllable parameters, which are the phase $\varphi$, the primary voltage width $\tau_{\mathrm{P}}$, and the secondary voltage width $\tau_{\mathrm{S}}$. The modulation is the most complex because there are many combinations of the same value of the fundamental phase $\varphi_{\mathrm{f}}$. Here, the analyzed modulation is only 


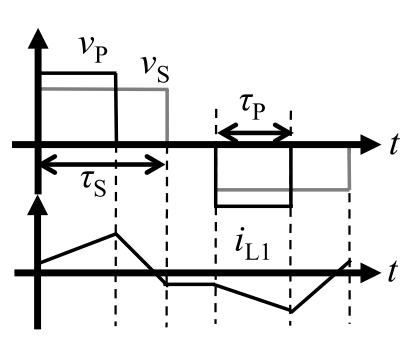

(a)

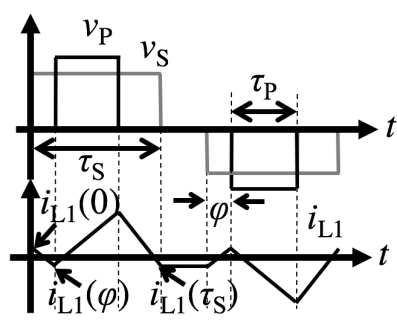

(b)

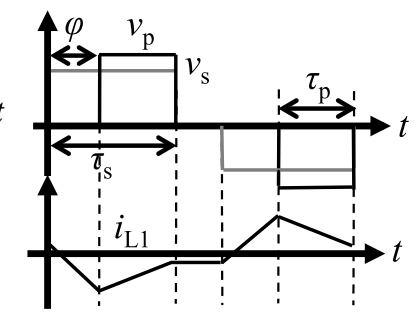

(c)

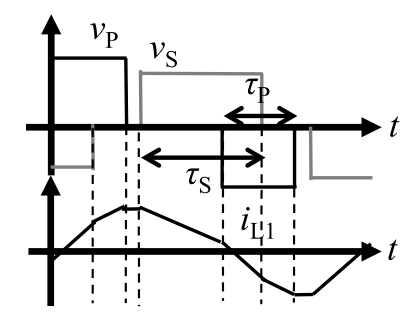

(d)

Fig. 4. Dual pulse-width modulation. (a) $\tau_{\mathrm{S}}>\tau_{\mathrm{P}}, r<1, \varphi=0$. (b) $\tau_{\mathrm{S}}>\tau_{\mathrm{P}}, r<1, \varphi<0$. (c) $\tau_{\mathrm{S}}>\tau_{\mathrm{P}}, r<1$, $\varphi<0$. (d) $\tau_{\mathrm{S}}>\tau_{\mathrm{P}}, r<1, \varphi>\tau_{P}(1-r) / 2$

Table 1. DPWM Current Analysis of Fig. 4(b)

\begin{tabular}{|c|c|}
\hline Phase interval & Current \\
\hline $0 \leq \theta \leq \varphi$ & $i_{\mathrm{L} 1}(\varphi)=-n V_{\mathrm{dc} 2} \varphi / \omega L_{1}+i_{\mathrm{Ll}}(0)$ \\
\hline$\varphi \leq \theta \leq \varphi+\tau_{\mathrm{P}}$ & $i_{\mathrm{L} 1}\left(\varphi+\tau_{\mathrm{P}}\right)=\left(V_{\mathrm{dcl}}-n V_{\mathrm{dc} 2}\right) \tau_{\mathrm{P}} / \omega L_{1}+i_{\mathrm{L} 1}(\varphi)$ \\
\hline$\varphi+\tau_{\mathrm{P}} \leq \theta \leq \tau_{\mathrm{S}}$ & $i_{\mathrm{L} 1}\left(\tau_{\mathrm{S}}\right)=-n V_{\mathrm{dc} 2}\left(\tau_{\mathrm{S}}-\varphi-\tau_{\mathrm{P}}\right) / \omega L_{1}+i_{\mathrm{L} 1}\left(\varphi+\tau_{\mathrm{P}}\right)$ \\
\hline \multicolumn{2}{|c|}{$i_{\mathrm{L} 1}(0)=\left(n V_{\mathrm{dc} 2} \tau_{\mathrm{S}}-V_{\mathrm{dc} 1} \tau_{\mathrm{P}}\right) / 2 \omega L_{1}$} \\
\hline
\end{tabular}

in the condition that is below (10) including the waveforms in Figs. 4(a), 4(b), and 4(c). Although the modulation in Fig. 4(d) operates fully in soft-switching, the peak current is higher than the other modes of the DPWM ${ }^{(22)}$. Only the modulation in Fig. 4(b) is analyzed because the analysis is also applicable to the modulations in Figs. 4(a) and 4(c) (positive and negative power transfers). The current analysis for the power transfer is given in Table 1. The power transfer is given by

$$
P_{\mathrm{o}}=\frac{r V_{\mathrm{dc1}}^{2}}{4 \pi^{2} f_{s} L_{1}}\left(2 \varphi \tau_{\mathrm{P}}-\tau_{\mathrm{P}}^{2}+\tau_{\mathrm{P}} \tau_{\mathrm{S}}\right)
$$

where the phase is less than zero, namely $\varphi<0$. This indicates that the power transfer depends on the three parameters. The peak current for the DPWM is

$$
i_{\text {peak }}=\frac{n V_{\mathrm{dc} 2}\left(\tau_{S}+2 \varphi-2 \tau_{\mathrm{P}}\right)+V_{\mathrm{dc} 1} \tau_{\mathrm{P}}}{4 \pi f_{\mathrm{S}} L_{1}}
$$

The peak current can be reduced to zero if $\varphi=\tau_{\mathrm{P}}=\tau_{\mathrm{S}}=$ 0 regardless the present voltage ratio. A lower current flowing through the transformer at low power transfer reduces the total losses in the power devices.

Reference (25) demonstrates that legs 1, 3, and 4 are operating in hard-switching at low power. From Fig. 4(b), the leakage current conditions $i_{\mathrm{L} 1}(\varphi)<0, i_{\mathrm{L} 1}(0)>0$, and $i_{\mathrm{L} 1}\left(\tau_{\mathrm{S}}\right)<0$ are needed to maintain the ZVS operation for all the power devices.

The ZVS condition for leg 1 is satisfied if the minimum value of the phase is

$$
\varphi_{\min }<\frac{1}{2}\left(\frac{\tau_{\mathrm{P}}}{r}-\tau_{\mathrm{S}}\right)
$$

The converter operates in the ZVS from $\varphi_{\min }<0$ if the primary voltage width satisfies $\tau_{\mathrm{P}}=\tau_{\mathrm{S}} r$. The phase shift must be negative to achieve the ZVS during positive and negative power transfers. In order to match $\varphi$ of the DPWM with that of the PSM and the SPWM, the phase is expressed using the fundamental value by using (1) and $\tau_{\mathrm{P}}=\tau_{\mathrm{S}} r$. The minimum fundamental phase for the DPWM is

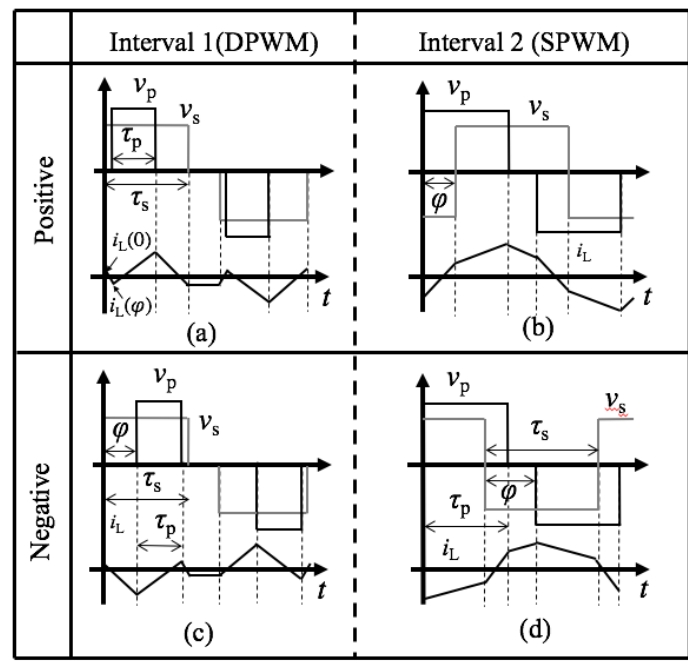

Fig. 5. Combined PWM waveform transition

$$
\varphi_{\mathrm{f}_{-} \min }<\frac{\tau_{\mathrm{P}}}{2 r}(1-r)=\frac{\tau_{\mathrm{S}}}{2}(1-r) .
$$

In the SPWM analysis, the primary voltage width does not affect the ZVS range. This implies that only the DPWM can increase the ZVS range in terms of the fundamental phase shift by reducing the value of secondary voltage width.

The soft-switching conditions for legs 3 and 4 are satisfied if the following condition is satisfied:

$$
\tau_{\mathrm{S}} r>\tau_{\mathrm{P}}
$$

This shows that the primary voltage width must be smaller than the secondary voltage width to achieve the ZVS operation in legs 3 and 4 . If the secondary voltage width is reduced, a lower power can be transferred in the ZVS.

\section{Proposed Modulation Strategy}

In this section, the SPWM and the DPWM are combined into one modulation strategy to operate in the ZVS and to reduce the circulating current. The modulation strategy is named the combined pulse-width modulation (CPWM). The waveform transition of the CPWM is shown in Fig. 5. The modulations are classified according to two fundamental phase intervals for positive and negative power transfers. The equations of three degrees of freedom $\left(\varphi, \tau_{\mathrm{P}}, \tau_{\mathrm{S}}\right)$ are calculated with the fundamental phase $\varphi_{\mathrm{f}}$ and the voltage ratio $r$ for each fundamental phase interval. Distinct from other modulation strategies, the bidirectional power flow is achieved by considering the equation for the phase $\varphi$. 


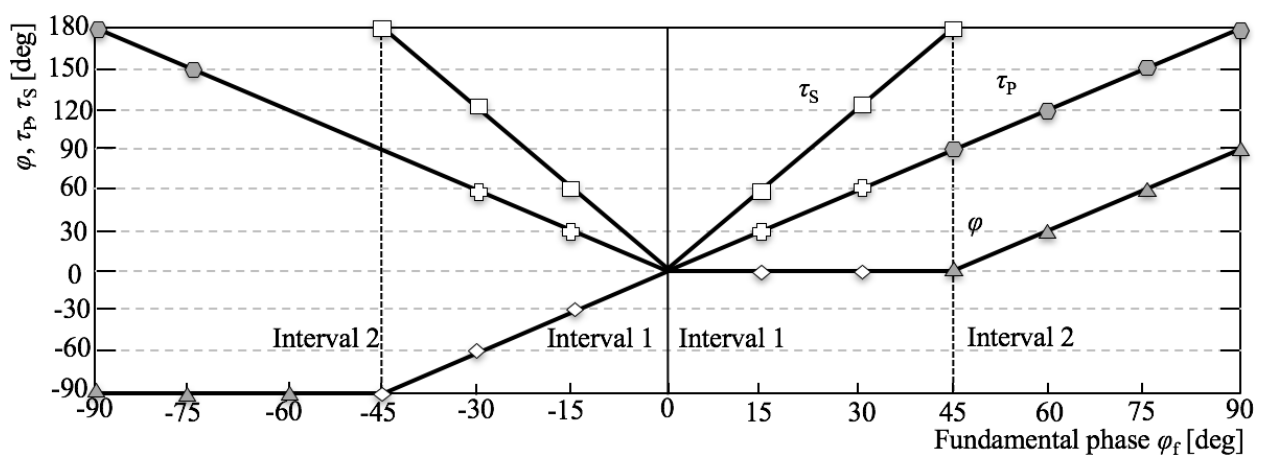

Fig. 6. Proposed modulation strategy for $r=0.5$

4.1 Fundamental Phase Interval Classification The analyses in Section 3 explain that the DAB dc-dc converter operates in the ZVS in a wide power range with the SPWM or the DPWM when the fundamental phase reaches the conditions in (10) or (14), respectively. This indicates that the modulations have their advantages and disadvantages in a particular fundamental phase range. In order for the CPWM to operate in the ZVS in a wide power range, the fundamental phase is divided into two intervals.

The first interval is for low to mid power transfer and the second interval is for mid to high power transfer. Each interval will consider the positive and negative power transfers. The boundary between the first interval and the second interval depends on the ZVS range in (10). The equation (10) implies that the boundary changes according to the voltage ratio $r$. The smaller the voltage ratio, the longer the first interval of CPWM.

The first fundamental phase interval for positive and negative low power transfer is

$$
\text { Interval } 1:-\frac{\pi}{2}(1-r)<\varphi_{\mathrm{f}}<\frac{\pi}{2}(1-r) . \cdots \ldots \ldots
$$

This interval is suitable for the DPWM because (14) proves that the soft-switching can be extended. In addition, it has the lowest current and power rating.

The second fundamental phase interval for positive and negative low power transfer is

$$
\text { Interval 2: } \begin{aligned}
-\frac{\pi}{2} & \leq \varphi_{\mathrm{f}} \leq-\frac{\pi}{2}(1-r) . \\
\frac{\pi}{2}(1-r) & \leq \varphi_{\mathrm{f}} \leq \frac{\pi}{2} .
\end{aligned} .
$$

The second interval is suitable for the SPWM and the PSM because (6) and (10) depict that both modulations can operate in the ZVS. The SPWM is used for the mid power transfer because it can transfer lower power and current with the same fundamental phase. The PSM is used for the full power transfer because it can transfer the highest power. Then the three degrees of freedom are calculated based on this fundamental phase interval classification.

4.2 CPWM Equation In this section, the three degrees of freedom, such as $\varphi, \tau_{\mathrm{P}}$, and $\tau_{\mathrm{S}}$, are calculated based on the fundamental phase $\varphi_{\mathrm{f}}$ and the voltage ratio $r$ for both intervals. The equations of the CPWM are summarized in Table 2. Figure 6 demonstrates the three parameters for $r=$ 0.5 .

In the interval 1, the parameters for the DPWM are calculated. When $\varphi_{\min }<0$ and (13) are considered, the relation
Table 2. Combined pulse-width modulation equation

\begin{tabular}{|c|c|c|}
\hline & Interval 1 & Interval 2 \\
\hline$\tau_{\mathrm{P}}$ & $\frac{2 r}{1-r}\left|\varphi_{\mathrm{f}}\right|$ & $\frac{1-r}{r}\left(2\left|\varphi_{\mathrm{f}}\right|-\pi\right)+\pi$ \\
\hline$\tau_{\mathrm{S}}$ & $\frac{2}{1-r}\left|\varphi_{\mathrm{f}}\right|$ & $\pi$ \\
\hline$\varphi$ & $\varphi_{\mathrm{f}}-\left|\varphi_{\mathrm{f}}\right|$ & $\varphi_{\mathrm{f}}+\frac{1-r}{2 r}\left(2\left|\varphi_{\mathrm{f}}\right|-\pi\right)$ \\
\hline
\end{tabular}

between the primary and secondary voltage widths is

$$
\tau_{\mathrm{P}}=r \tau_{\mathrm{S}}
$$

Although (13) stated that the phase must be negative, the phase is set to zero to avoid a discontinuous modulation strategy ${ }^{(26)}$. Therefore, the hard-switching will still occur in the interval 1.

From (1), (18), and $\varphi_{\min }=0$, the primary and secondary voltage widths can be calculated for positive and negative power transfers. The primary and secondary widths are,

$$
\tau_{\mathrm{S}}=\frac{2}{1-r}\left|\varphi_{\mathrm{f}}\right| \text { and } \tau_{\mathrm{P}}=\frac{2 r}{1-r}\left|\varphi_{\mathrm{f}}\right|
$$

The primary and secondary voltage widths consider the absolute fundamental phase because the primary and secondary voltage width are always positive regardless the sign of the fundamental phase. The consideration of the absolute fundamental made the calculation for the phase in the interval 1 to be possible. The phase is calculated by using (1) and (19) to be

$$
\varphi=\varphi_{\mathrm{f}}-\left|\varphi_{\mathrm{f}}\right| \cdot
$$

When the fundamental phase and the secondary voltage width reach $\pm \pi(1-r) / 2$ and $\pi$, respectively, the CPWM enters the second interval.

In the interval 2, the SPWM is combined with the PSM. In summary, the fundamental phase starts from $\pi(1-r) / 2$ to $\pi / 2$, while the primary voltage starts from $r \pi$ to $\pi$. The linear variation and gradient comparison of the primary voltage width to the fundamental phase yields

$$
\tau_{\mathrm{P}}=\frac{1-r}{r}\left(2\left|\varphi_{\mathrm{f}}\right|-\pi\right)+\pi \text {. }
$$

The primary voltage width in the second interval also considers the absolute fundamental phase because the primary voltage width is always positive regardless the sign of the 


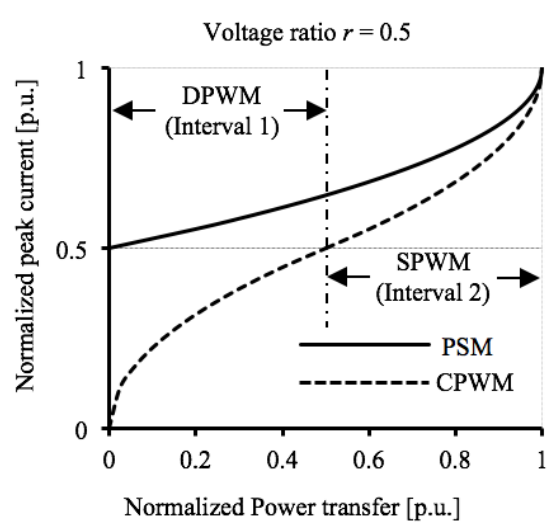

Fig. 7. Normalized peak current varied with normalized power transfer of CPWM and PSM

fundamental phase. The phase is calculated by using (1), (21), and $\tau_{\mathrm{S}}=\pi$ to be

$$
\varphi=\varphi_{\mathrm{f}}+\frac{(1-r)}{2 r}\left(2\left|\varphi_{\mathrm{f}}\right|-\pi\right) . \cdots \cdots \cdots \cdots \cdots \cdots \cdots
$$

The phase changes from 0 to 90 when the fundamental phase is 45 to 90 , respectively while the phase maintains at 90 when the fundamental phase is -45 to -90 , respectively when the voltage ratio is $r=0.5$.

The CPWM combines the three modulation strategies based on the soft-switching boundary and reduces the peak current for a wide power range. Figure 7 are the peak current varied with power transfer of the PSM and that of the CPWM. The dashed line represents the DPWM and the dotted line represents the SPWM. Both of the connected lines represents the CPWM. The boundary between the DPWM and the SPWM depends on (6). The DPWM and the SPWM corresponds to the interval 1 and interval 2, respectively. The proposed modulation strategy indicates an overall lower peak current than the PSM.

Distinct from the modulation strategy in (23), an absolute value of the fundamental phase is considered in the equations to transfer power bidirectionally.

\section{Simulation}

A simulation is carried out to verify if there is a surge or pulsation when the converter is operating in the hardswitching. The verification is important before choosing a suitable power device. The parameters of the simulation are in Table 3. Since the PSM and the CPWM operate in the hard-switching only during the interval 1 , we focus the waveforms of the simulation under the condition that the output power is $600 \mathrm{~W}$ and $-600 \mathrm{~W}$.

The waveforms of the simulation with the PSM and the CPWM during interval 1 are shown in Figs. 9 and 10, respectively. The hard-switching operation is observed during the simulation. The hard-switching points are marked with red circle points. The output power of Figs. 9(a) and (b) are $600 \mathrm{~W}$ and $-600 \mathrm{~W}$, respectively. Figures 9 (a) and (b) show that the leakage inductance currents at $i_{\mathrm{L} 1}(\varphi)$ and $i_{\mathrm{L} 1}(\varphi+\pi)$ do not satisfy the ZVS conditions $\left(i_{\mathrm{L} 1}(\varphi)>0\right.$ and $i_{\mathrm{L} 1}(\varphi+\pi)<0$, respectively). The leg 3 and leg 4 of the converter are operating in the hard-switching. The output power of Figs. 10(a) and (b) are $600 \mathrm{~W}$ and $-600 \mathrm{~W}$, respectively. Figure 10(a)

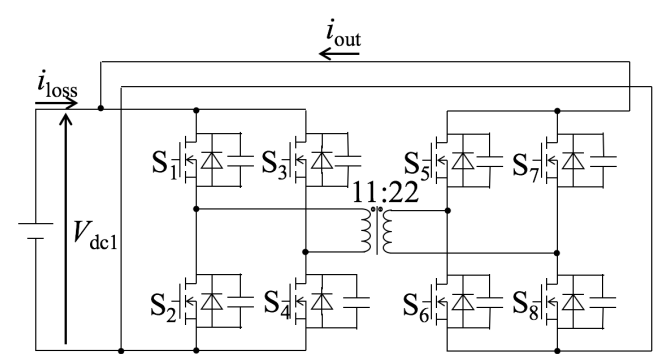

Fig. 8. Dual active bridge circuit

Table 3. Parameters

\begin{tabular}{|c|c|}
\hline Primary voltage $\left(V_{\mathrm{dc} 1}\right)$ & $380 \mathrm{~V}$ \\
\hline Power capability $(P)$ & $1.6 \mathrm{~kW}$ \\
\hline Dead time $\left(t_{\mathrm{d}}\right)$ & $0.24 \mu \mathrm{s}\left(3.5^{\circ}\right)$ \\
\hline Voltage ratio $\left(r=n V_{\mathrm{dc} 2} / V_{\mathrm{dc} 1}\right)$ & 0.5 \\
\hline Winding ratio $\left(N_{\mathrm{P}}: N_{\mathrm{s}}\right)$ & $11: 22$ \\
\hline Switching frequency $(f)$ & $80 \mathrm{kHz}$ \\
\hline Parasitic capacitance & $175 \mathrm{pF}$ \\
\hline Transformer leakage inductance $\left(L_{1}\right)$ & $70 \mu \mathrm{H}$ \\
\hline
\end{tabular}

shows that the leakage inductance current at $i_{\mathrm{L} 1}(0)$ and $i_{\mathrm{L} 1}(\pi)$ do not satisfy the ZVS condition $\left(i_{\mathrm{L} 1}(0)<0\right.$ and $\left.i_{\mathrm{L} 1}(\pi)>0\right)$. The leg 1 of the converter is operating in the hard-switching. Figure $10(\mathrm{~b})$ shows that the leakage inductance currents at $i_{\mathrm{L} 1}(\varphi), i_{\mathrm{L} 1}\left(\tau_{\mathrm{P}}+\pi-\tau_{\mathrm{S}}\right), i_{\mathrm{L} 1}\left(\tau_{\mathrm{P}}+\pi\right)$, and $i_{\mathrm{L} 1}\left(\tau_{P}\right)$ do not satisfy the ZVS conditions $\left(i_{\mathrm{L} 1}(\varphi)>0, i_{\mathrm{L} 1}\left(\tau_{\mathrm{P}}+\pi-\tau_{\mathrm{S}}\right)<0\right.$, $i_{\mathrm{L} 1}\left(\tau_{P}+\pi\right)>0$, and $i_{\mathrm{L} 1}\left(\tau_{P}\right)<0$, respectively). The leg 3 and leg 4 of the converter are operating in the hard-switching. Although the converter is operating in the hard-switching, there is no surge in the simulation result.

\section{Experiments}

6.1 Prototype and Controller In this research, a prototype is designed for a bidirectional power transfer of $1.6 \mathrm{~kW}$. The main circuit is shown in Fig. 8. The parameters are summarized in Table 3 . The core of the transformer is a toroidal core (FINEMET, Hitachi Metals). The leakage inductance is $70 \mu \mathrm{H}$. The primary to secondary winding ratio is 11:22. The primary and secondary voltages are fixed at $380 \mathrm{~V}$. This experimental configuration enables the bidirectional power transfer more than $1 \mathrm{~kW}$ with a single regenerative power supply. In this case, the voltage ratio $r$ becomes 0.5 . This condition is chosen to operate the converter in an unfavorable voltage variation scenario while the convenient condition is $r=1$. In addition, when the voltage ratio is 0.5 , the boundary becomes $\pi / 4$ from (6) which is the half of the maximum power phase $\pi / 2$. It is easier to observe the difference between the DPWM and the SPWM when interval 1 (from 0 to $\pi / 4$ ) and interval 2 (from $\pi / 4$ to $\pi / 2$ ) have an equal range. The dead time interval is fixed at $0.24 \mu \mathrm{s}$. All the power devices $\left(\mathrm{S}_{1}\right.$ to $\left.\mathrm{S}_{8}\right)$ in $\mathrm{FB} 1$ and $\mathrm{FB} 2$ are SiC MOSFETs (SCH2080KE, ROHM).

An experiment is conducted to validate the bidirectional power transfer capability of CPWM. The efficiency and power transfer of the prototype are measured with a precision power analyzer (WT1800, YOKOGAWA). The entire control is implemented with a digital processor (TMS320F28335, TI).

6.2 Experimental Results In this experiment, the 


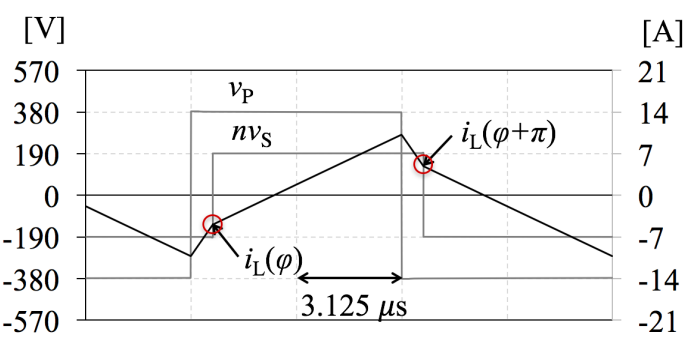

(a)
[V]

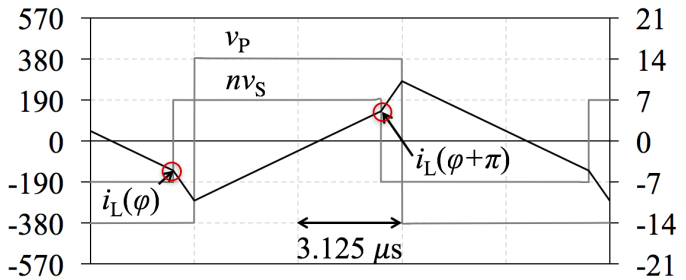

(b)

Fig. 9. Simulation waveforms of PSM during (a) $600 \mathrm{~W}$. (b) $-600 \mathrm{~W}$

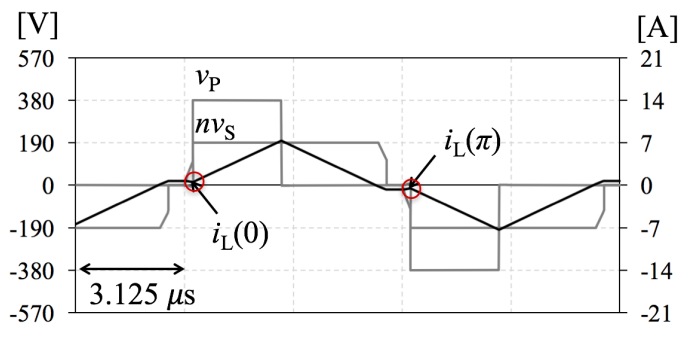

(a)

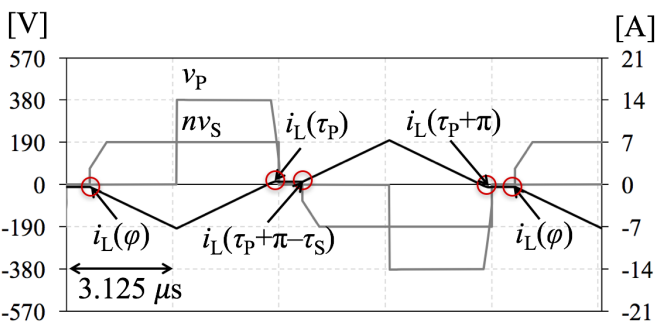

(b)

Fig. 10. Simulation waveforms of CPWM during (a) $600 \mathrm{~W}$. (b) $-600 \mathrm{~W}$

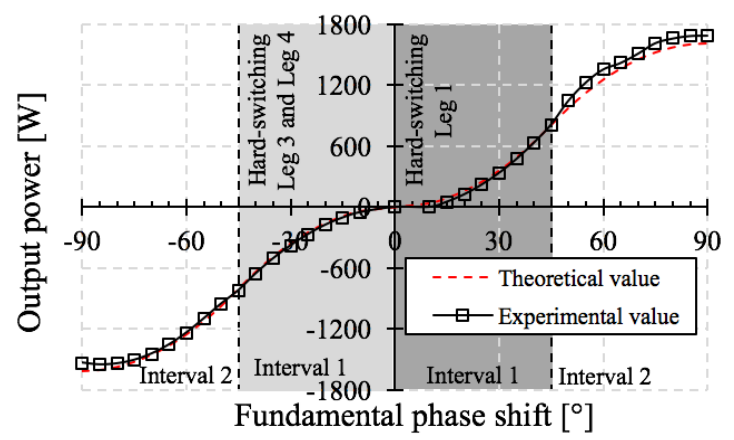

Fig. 11. Power transfer of CPWM varied with fundamental phase

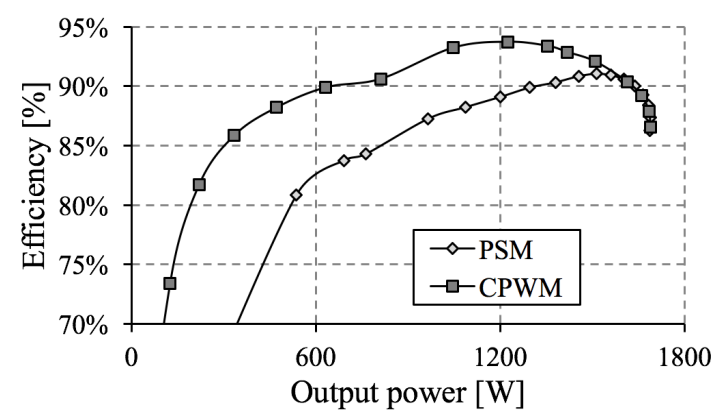

Fig. 12. The efficiency of CPWM and PSM varied with positive power transfer

power is bidirectionally transferred by shifting the fundamental phase from $-90^{\circ}$ to $90^{\circ}$ with the CPWM. Figure 11 compares the experimental data are nearly equal. This justifies the correctness of (7) and (11). The hard-switching operation is highlighted with light and dark gray shaded areas. The dark gray shaded area between $0^{\circ}$ to $45^{\circ}$ represents that the power devices in leg 1 are in the hard-switching. The light gray shaded area between $-45^{\circ}$ to $0^{\circ}$ illustrates that the power devices in leg 3 and leg 4 are in the hard-switching.

Figsures 12 and 13 compare the experimentally measured efficiencies under the CPWM for a bidirectional power flow

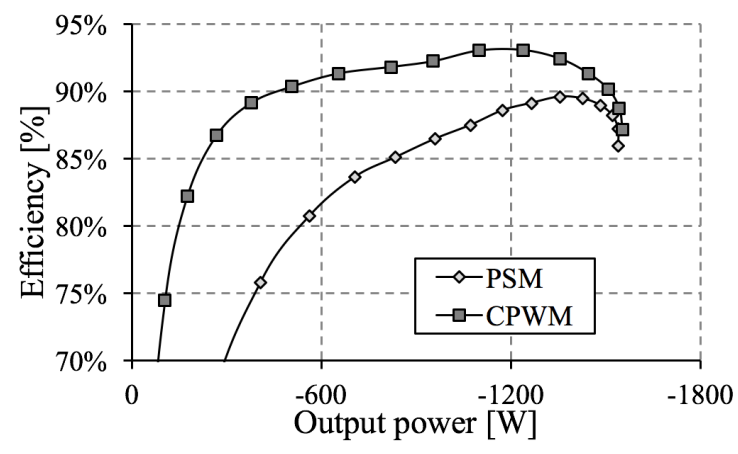

Fig. 13. The efficiency of CPWM and PSM varied with negative power transfer

from $-1600 \mathrm{~W}$ to $1600 \mathrm{~W}$. The efficiency during positive and negative power transfers improves by about $10 \%$ with the CPWM. The total power loss of the CPWM is about $50 \mathrm{~W}$ lesser than that in the PSM. This result confirms that the CPWM increases the overall efficiency even when there is voltage variation in the system.

Figures 14, and 15 show the experimental waveforms of the PSM and CPWM. The hard-switching points are marked with red circles. Figures 14 and 15 confirm that the peak current of the CPWM is lower than that of the PSM for medium and high power transfer ( $600 \mathrm{~W}$ and $1500 \mathrm{~W}$, respectively). The hard-switching operation is observed during the experiment. Figure 14(a) confirms that the leakage inductance current at $i_{\mathrm{L} 1}(\varphi)$ and $i_{\mathrm{L} 1}(\varphi+\pi)$ are not satisfying the ZVS conditions $\left(i_{\mathrm{L} 1}(\varphi)>0\right.$ and $i_{\mathrm{L} 1}(\varphi+\pi)<0$, respectively). The leg 3 and leg 4 of the converter are operating in the hardswitching at $600 \mathrm{~W}$. Figure 15(a) confirms that the leakage inductance current at $i_{\mathrm{L} 1}(0)$ and $i_{\mathrm{L} 1}(\pi)$ are not satisfying the ZVS condition $\left(i_{\mathrm{L} 1}(0)<0\right.$ and $\left.i_{\mathrm{L} 1}(\pi)>0\right)$. The leg 1 of the converter is operating in the hard-switching at $600 \mathrm{~W}$. Figure 15(c) confirms that the leakage inductance current at $i_{\mathrm{L} 1}(\varphi), i_{\mathrm{L} 1}\left(\tau_{P}+\pi-\tau_{\mathrm{S}}\right), i_{\mathrm{L} 1}\left(\tau_{P}+\pi\right)$, and $i_{\mathrm{L} 1}\left(\tau_{P}\right)$ are not satisfying the ZVS conditions $\left(i_{\mathrm{L} 1}(\varphi)>0, i_{\mathrm{L} 1}\left(\tau_{P}+\pi-\tau_{\mathrm{S}}\right)<0\right.$, 
$[\mathrm{V}]$

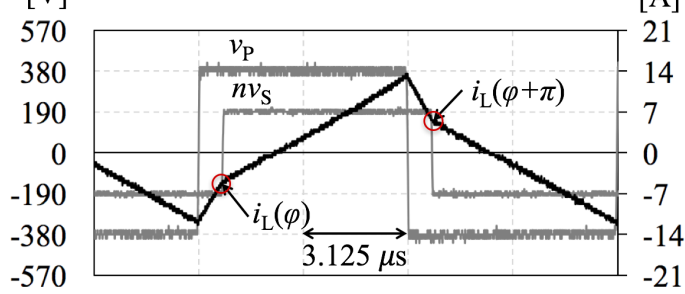

(a)

\section{[V]}

570
380
190
0
-190
-380
-570

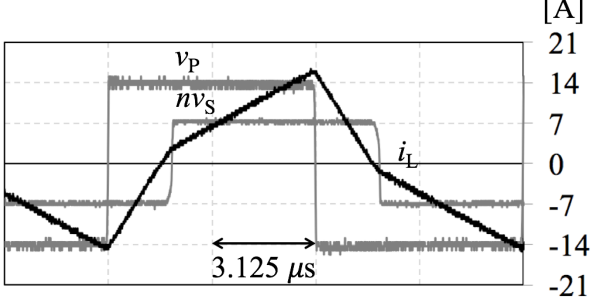

(b)

Fig. 14. Experimental waveforms of PSM during (a) $600 \mathrm{~W}$. (b) $1400 \mathrm{~W}$

$[\mathrm{V}]$

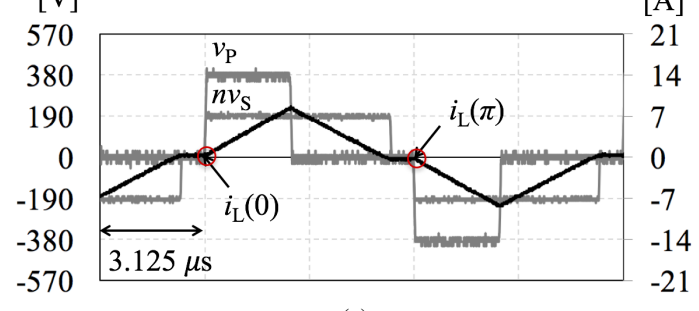

(a)

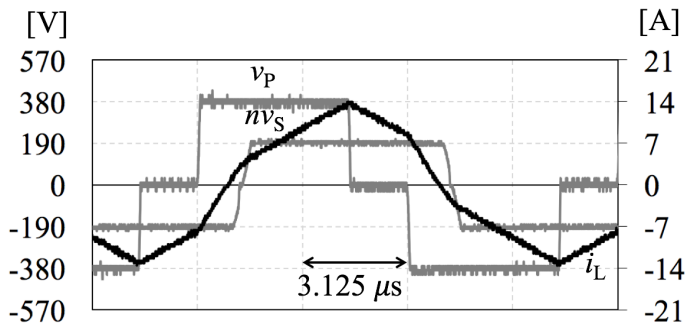

(b)

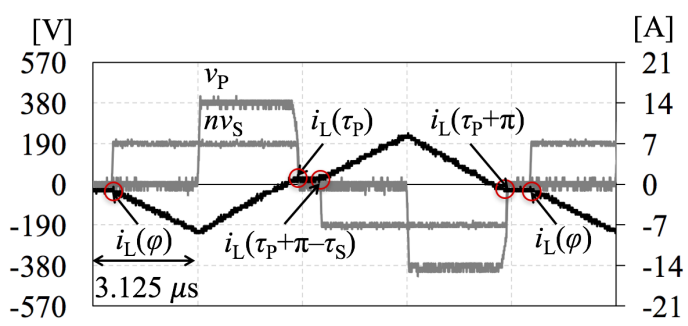

(c)

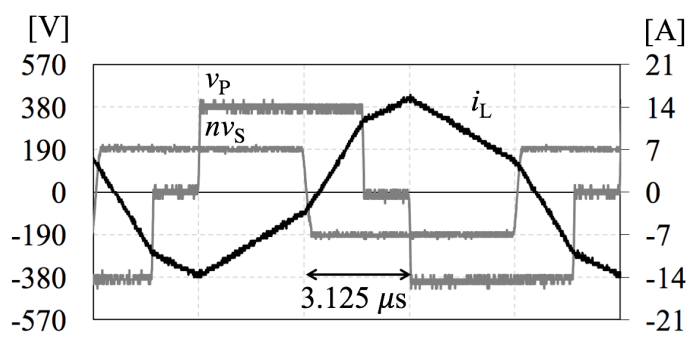

(d)

Fig. 15. Experimental waveforms of the CPWM during (a) $600 \mathrm{~W}$. (b) $1400 \mathrm{~W}$. (c) $-600 \mathrm{~W}$. (d) $-1400 \mathrm{~W}$
$i_{\mathrm{L} 1}\left(\tau_{P}+\pi\right)>0$, and $i_{\mathrm{L} 1}\left(\tau_{P}\right)<0$, respectively). The leg 3 and leg 4 of the converter are operating in the hard-switching at $-600 \mathrm{~W}$. The surge is also not present in the positive and negative power transfer with CPWM and PSM during the hardswitching operation.

\section{Conclusion}

This paper has proposed a new modulation strategy, the CPWM by combining the SPWM and the DPWM to transfer power bidirectionally with low peak current even if there is a wide voltage variation. For this purpose, the SPWM and the DPWM are comprehensively analyzed. The advantages of the CPWM are verified by the simulation and the experiment with a $1.6 \mathrm{~kW}$ prototype. The bidirectional power transfer is successfully done with the CPWM. The experimental results confirm that the efficiency of positive and negative power transfer improves by about $10 \%$ with the CPWM. Our future research is to improve the CPWM to accomplish the ZVS operation in the interval 1.

This research is supported by JST Super Cluster Program.

\section{References}

( 1 ) F.H. Khan, L.M. Tolbert, and W.E. Webb: "Hybrid electric vehicle power management solutions based on isolated and nonisolated configurations of multilevel modular capacitor-clamped converter", IEEE Trans. on Industrial Electronics, Vol.56, No.8, pp.3079-3095 (2009)

( 2 ) S.B. Monge, S. Alepuz, and J. Bordonau: "A bidirectional multilevel boostbuck DC-DC converter", IEEE Trans. on Power Electronics, Vol.26, No.8, pp.2172-2183 (2011)

( 3 ) F.Z. Peng, F. Zhang, and Z. Qian: "A magnetic-less DC-DC converter for dual voltage automotive system", IEEE Trans. on Industry Applications, Vol.39, No.2, pp.511-518 (2003)

( 4 ) Y.S. Lee and Y.Y. Chiu: "Zero-current-switching switched-capacitor bidirectional DC-DC converter", IEE Proc.-Electr. Power Appl., Vol.152, No.6, pp.1525-1530 (2005)

( 5 ) Y.P. Ko, Y.S. Lee, and W.H. Chao: "Analysis, design and implementation of fuzzy logic controlled quasi-resonant zero-current switching switchedcapacitor bidirectional converter", IET Power Electron., Vol.4, No.6, pp.683692 (2010)

( 6 ) K. Venkatesan: "Current mode controlled bidirectional flyback converter", Proc. IEEE PESC., pp.835-842 (1989)

( 7 ) G. Chen, Y.S. Lee, S.Y.R. Hui, D. Xu, and Y. Wang: "Actively clamped bidirectional flyback converter", IEEE Trans. on Industrial Electronics, Vol.47, No.4, pp.770-779 (2000)

( 8 ) L. Huber and M.M. Jovanovic: "Forward-flyback converter with currentdoubler rectifier: analysis, design, and evaluation results", IEEE Trans. on Power Electronics, Vol.14, No.1, pp.184-192 (1999)

( 9 ) F. Zhang and Y. Yan: "Novel forward-flyback hybrid bidirectional DC-DC converter", IEEE Trans. on Industrial Electronics, Vol.56, No.5, pp.15781584 (2009)

(10) H. Li, F.Z. Peng, and J.S. Lawler: "A natural ZVS medium-power bidirectional DC-DC converter with minimum number of devices", IEEE Trans. on Industry Applications, Vol.39, No.2, pp.525-535 (2003)

(11) F.Z. Peng, H. Li, G.J. Su, and J.S. Lawler: "A new ZVS bidirectional DCDC converter for fuel cell and battery application”, IEEE Trans. on Power Electronics, Vol.19, No.1, pp.54-65 (2004)

(12) B.R. Lin, C.L. Huang, and Y.E. Lee: "Asymmetrical pulse-width modulation bidirectional DC-DC converter", IET Power Electron., Vol.1, No.3, pp.336347 (2008)

(13) C. Mi, H. Bai, C. Wang, and S. Gargies: "Operation, design and control of dual H-bridge-based isolated bidirectional DC-DC converter", IET Power Electron., Vol.1, No.4, pp.507-517 (2008)

(14) C. Zhao, S.D. Round, and J.W. Kolar: "Full-order averaging modelling of zero-voltage-switching phase-shift bidirectional DC-DC converters", IET Power Electron., Vol.3, No.3, pp.400-410 (2010)

(15) R.W.A.A. De Doncker, D.M. Divan, and M.H. Kheraluwala: "A three-phase soft-switched high-power-density DC/DC converter for high-power applications", IEEE Trans. on Industry Applications, Vol.27, No.1, pp.63-73 (1991) 
(16) F. Krismer, S. Round, and J.W. Kolar: "Performance optimization of a high current dual active bridge with a wide operating voltage range", Proc. 37th IEEE Power Electron. Special. Conf., pp.1-7 (2006)

(17) G.G. Oggier, R. Leidhold, G.O. García, A.R. Oliva, J.C. Balda, and F. Barlow: "Extending the ZVS operating range of dual active bridge highpower DC-DC converters", PESC Rec.-IEEE Ann. Power Electron. Spec. Conf., pp.2-8 (2006)

(18) G.G. Oggier, G.O. Garcia, and A.R. Oliva: "A magnetic-less DC-DC converter for dual voltage automotive system", IEEE Trans. on Power Electron., Vol.24, No.7, pp.1826-1838 (2009)

(19) H. Bai and C. Mi: "Eliminate reactive power and increase system efficiency of isolated bidirectional dual-active-bridge dc-dc converters using novel dual-phase-shift control", IEEE Trans. on Power Electron., Vol.23, No.6, pp.2905-2914 (2008)

(20) J. Huang, Y. Wang, Y. Gao, W. Lei, and Y. Li: "Unified triple-phase-shift control to minimize current stress and achieve full soft-switching of isolated bidirectional dc-dc converters", IEEE Trans. on Industrial Electronics, Vol.63, No.7, pp.4169-4179 (2016)

(21) F. Jauch and J. Biela: "Generalized modeling and optimization of a bidirectional dual active bridge DC-DC converter including frequency variation", IEEJ Journal of Ind. Appl., Vol.4, No.5, pp.592-601 (2015)

(22) H. Zhou and A.M. Khambadkone: "Hybrid modulation for dual-activebridge bidirectional converter with extended power range for ultracapacitor application", IEEE Trans. on Industry Applications, Vol.45, No.4, pp.14341442 (2009)

(23) A.K. Jain and R. Ayyanar: "PWM control of dual active bridge: comprehensive analysis and experimental verification", IEEE Trans. on Power Electron., Vol.26, No.4, pp.1215-1227 (2008)

(24) F. Krismer and J.W. Kolar: "Closed form solution for minimum conduction loss modulation of DAB converter", IEEE Trans. on Power Electron., Vol.27, No.1, pp.174-188 (2012)

(25) M.H.A. bin Ab Malek and H. Kakigano: "Fundamental study on control strategies to increase efficiency of dual active bridge DC-DC converter", Industrial Electronics Society, IECON $2015-41^{\text {st }}$ Annual Conference of the IEEE, pp.1073-1078 (2015)

(26) F. Krismer and J.W. Kolar: "Efficiency-optimized high-current dual active bridge converter for automotive applications", Industrial IEEE Trans. on Industrial Electronics, Vol.59, No.7, pp.2745-2760 (2012)
Muhammad Hazarul Azmeer bin Ab Malek (Member) was born in

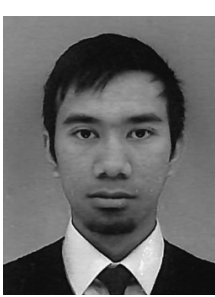
1991 in Pahang, Malaysia. He received a B.S. and M.S. degrees from Ritsumeikan University, Shiga, Japan in 2014 and 2016, respectively. He is currently engaged in a project on dual active bridge dc-dc converter as a postgraduate student at Ritsumeikan University.

Hiroaki Kakigano (Member) received B.S. and M.S. degrees from

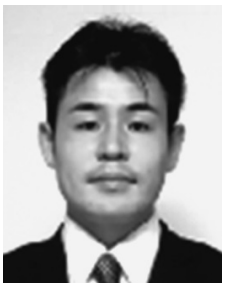
Nagoya University in 1999 and 2001, respectively. After joining a company as an engineer, he entered a doctorate course at Osaka University in 2006 . He received a Ph.D. degree in electrical engineering from Osaka University in 2009. Since 2013, he has been an associate professor at Ritsumeikan University. His research interests are in power electronics for power system applications.

Kiyotsugu Takaba (Member) received his B.Eng., M.Eng., and

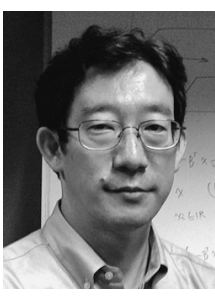
Dr.Eng. degrees all from Kyoto University, Japan, in 1989, 1991, and 1995, respectively. From 1991 to 1998, he was an Assistant Professor at the Department of Applied Mathematics and Physics, Kyoto University. From 1998 to 2012, he was an Associate Professor at the same department. In 2012, he joined the Department of Electrical and Electronic Engineering, Ritsumeikan University, where he is currently a Professor. His current research interests include robust control, optimal control, multi-agent control systems, and their application to practical systems. He is a member of IEEE, SIAM, SICE, and ISCIE. 